Research Article

\title{
Relationship of Serum Total Insulin-Like Growth Factor Binding Protein-3 with Insulin-Like Growth Factor-I and Glucose Tolerance in Korean Children and Adolescents
}

\author{
Sun-Young Kim, ${ }^{1}$ Minsun Kim ${ }^{D},{ }^{1,2}$ Youngman $\mathrm{Oh}^{3}$ and Dae-Yeol Lee ${ }^{2}$ \\ ${ }^{1}$ Research Institute of Clinical Medicine of Jeonbuk National University-Biomedical Research Institute \\ of Jeonbuk National University Hospital, Jeonju 54907, Republic of Korea \\ ${ }^{2}$ Department of Pediatrics, Jeonbuk National University Medical School, Jeonju 54907, Republic of Korea \\ ${ }^{3}$ Department of Pathology, School of Medicine Medical College of Virginia Campus, Virginia Commonwealth University, \\ Richmond, VA 23298, USA \\ Correspondence should be addressed to Minsun Kim; children@jbnu.ac.kr
}

Received 16 March 2021; Accepted 12 June 2021; Published 22 June 2021

Academic Editor: Flavia Prodam

Copyright (c) 2021 Sun-Young Kim et al. This is an open access article distributed under the Creative Commons Attribution License, which permits unrestricted use, distribution, and reproduction in any medium, provided the original work is properly cited.

\begin{abstract}
Insulin is important in glucose metabolism. However, insulin-like growth factor binding protein (IGFBP) also plays an important role in glucose homeostasis, although the IGF-independent role of IGFBP-3 in the glucose intolerance state is poorly understood. We investigated the relationship of serum IGF-I with total IGFBP-3 levels and glucose tolerance in Korean children and adolescents who underwent the oral glucose tolerance test (OGTT). A total of 187 children without known diabetes underwent OGTT, and data related to their clinical and laboratory parameters were collected. Serum IGF-I and total IGFBP-3 levels, fasting plasma glucose levels, lipid profiles, insulin levels, C-peptide levels, homeostasis model assessment of insulin resistance (HOMAIR) index, and glycated hemoglobin (HbA1c) levels were measured. Serum IGF-I and total IGFBP-3 levels were significantly higher in individuals with impaired glucose tolerance and type 2 diabetes (DM) than in those with normal glucose tolerance (NGT) $(P<0.05)$. Serum IGF-I and IGFBP-3 levels were correlated with age, HbA1c, C-peptide, insulin, and HOMA-IR in the NGT group. However, these relationships were altered in patients with glucose intolerance, especially in those with DM. In the DM group, serum IGF-I and total IGFBP-3 levels were positively correlated with fasting plasma glucose and HbA1c levels. In addition, total IGFBP-3 levels were positively correlated with total cholesterol and low-density lipoprotein cholesterol and IGF-I levels but not with age or body mass index. The IGF-I-IGFBP-3 axis, especially IGFBP-3, may be involved in the pathogenesis and metabolic control of glucose intolerance, specifically in diabetes patients. Moreover, IGFBP-3 might be a therapeutic marker.
\end{abstract}

\section{Introduction}

Type 1 diabetes is the most common hyperglycemic disease in children and adolescents, but the incidence of type 2 diabetes has significantly increased due to the recent increase in childhood obesity [1]. Recently, in Korea, the frequency of type 2 diabetes and prediabetes has also increased in teenagers and young adults [2]. Thus, it is important to determine the factors that affect their diagnosis and treatment, control these factors, and find factors that can be used as treatment targets in children and adolescents.
The insulin-like growth factor (IGF) system is important in the regulation of growth and cellular proliferation in the human body [3, 4]. The IGF system includes IGF-I/II peptides, IGF-I and IGF-II receptors, and IGF-binding proteins (IGFBPs) [5-7]. IGFBPs are classified into two groups: a binding protein (IGFBP-1 to -6 ) that has a high affinity for IGF and an IGFBP-related protein (IGFBP-rP110 and IGFBP-rP1, also known as IGFBP-7) that has a low affinity for IGF [8]. IGFBPs transport IGFs to their receptors $[8,9]$. The pivotal IGFBP species in the serum is IGFBP-3; it binds to $90 \%$ or more of circulating IGF-I and makes a large 
ternary complex with acid-labile subunits and IGFs [8, 10]. Furthermore, IGFBP-3 has shown cell growth inhibition and apoptosis by IGF-independent activity in various cell types [11]. It has been reported that the IGF-I/IGFBP-3 ratio can be used as an important indicator for the effect of growth hormone treatment in children [12], but there are limited studies conducted in conditions such as metabolic abnormalities and diabetes.

IGF-I may be involved in maintaining glucose homeostasis and lipid metabolism. IGF-I increases insulin sensitivity, peripheral glucose levels, and fatty acid uptake and decreases hepatic glucose production [13]. In addition, positive correlations have been reported between insulin resistance and increased IGF-I levels among patients with diabetes $[14,15]$. A study reported that low and high IGF-I levels were both related to a greater risk of type 2 diabetes (DM) [16]. Rajpathak et al. reported a positive association between IGFBP-3 and the risk of DM in women [17]. However, the precise mechanisms of action of IGF-I and IGFBP-3 in DM remain elusive.

In this study, we investigated the relationships of serum IGF-I with total IGFBP-3 levels and glucose tolerance in children and adolescents.

\section{Materials and Methods}

In total, 191 children and adolescents who visited Jeonbuk National University Children's Hospital to diagnose DM by the oral glucose tolerance test (OGTT) during 2010-2018 were initially included. Subjects were excluded from this study if they had been previously diagnosed with diabetes or had diabetic symptoms (such as polyuria, polydipsia, hyperphagia, and weight loss), ketogenesis, or other chronic diseases. Furthermore, three subjects with positive results for the diabetes-related autoantibodies test such as glutamic acid decarboxylase, islet cell, and insulin antibodies and one subject with the fasting serum C-peptide level under $0.6 \mathrm{ng}$ / $\mathrm{mL}$ were also excluded. Finally, 187 children and adolescents (aged 10.08-17.60 years) were enrolled; of these, 130 visited the hospital to undergo glucosuria examination based on school urinary glucose screening [18-21], while the other 57 were referred for obesity checkup. A large-scale school urine screening program was implemented in the Jeonbuk Province area. Glucose oxidase tape (UriScan, YD Diagnostic Corporation, Yongin, South Korea) was used to examine the morning urine samples for glycosuria [18]. If the first urine test result was positive, a second urine test was performed within two weeks. If the second test result was positive, students were recommended to visit the hospital for further evaluation. This study followed a retrospective design. According to the OGTT results, subjects were divided into the normal glucose tolerance (NGT) group and the glucose intolerance group; the latter comprised subjects with impaired glucose tolerance (IGT) and DM.

Subjects' medical history and physical examination were based on their first visit to the hospital. Anthropometrics and body mass index (BMI) were measured by two trained pediatric endocrinologists and compared with the data in the 2017 Korean National Growth Charts [22]. Height (cm) was measured with a Harpenden Stadiometer (Holtain Ltd., Crymych, Wales, UK), and weight (kg) was measured with a digital scale (150 A; Cas Co., Ltd., Seoul, Korea). Height and weight were measured to the nearest $0.1 \mathrm{~cm}$ and $0.1 \mathrm{~kg}$, respectively. BMI was calculated as weight in kilograms divided by height in meters squared $\left(\mathrm{kg} / \mathrm{m}^{2}\right)$. Overweight was defined as 85 th $\leq \mathrm{BMI}<95$ th by age- and sex-specific percentile, while obesity was defined as $\mathrm{BMI} \geq 95$ th percentile. OGTT $(1.75 \mathrm{~g} / \mathrm{kg}$, maximum $75 \mathrm{~g}$ of glucose) was conducted in the morning after fasting for 12 hours. The diagnostic criteria for DM were 2-hour postload glucose ( $2 \mathrm{hr}$ PLG) level $\geq 200 \mathrm{mg} / \mathrm{dL}$ or fasting plasma glucose (FPG) level $\geq 126 \mathrm{mg} / \mathrm{dL}$; IGT was defined as $2 \mathrm{hr}$ PLG level of $140-199 \mathrm{mg} / \mathrm{dL}$ and NGT as $2 \mathrm{hr}$ PLG level $<140 \mathrm{mg} / \mathrm{dL}$ according to the World Health Organization criteria based on primary OGTT findings [23]. All the patients had negative test results for diabetes-related autoantibodies, with no evidence of ketogenesis, and a fasting serum C-peptide level above $0.6 \mathrm{ng} / \mathrm{mL}$ [24]. Serum IGF-I and total IGFBP-3 levels were measured using enzyme-labeled chemiluminescence immunoassay (IGF-I, DiaSorin SPA, Italy; IGFBP-3, Siemens Medical Solutions Diagnostics, USA).

In addition, FPG, total cholesterol, low-density lipoprotein (LDL) cholesterol, high-density lipoprotein (HDL) cholesterol, triglyceride, insulin, C-peptide, and glycated hemoglobin (HbA1c) levels were measured. Insulin sensitivity was measured using the homeostasis model assessment of insulin resistance (HOMA-IR) index [25].

The study was approved by the Institutional Review Board (IRB) of Jeonbuk National University Research Council (IRB no. 2019-09-028); the need for informed consent was waived by the IRB.

2.1. Statistical Analysis. All variables are expressed as mean \pm standard deviation (SD). One-way analysis of variance and Tukey's test were performed to evaluate OGTT and BMI in all groups using the SPSS software (version 19.0, SPPS, Chicago, IL, USA). The relationships between IGF-I/ IGFBP-3 with clinical and laboratory variables were estimated using Pearson correlation coefficients. Statistical significance was set at a $P$ value of $<0.05$.

\section{Results}

The demographic features of a total of 187 school children and adolescents are given in Table 1. Among the 187 subjects, 33 were diagnosed with IGT and 39 were diagnosed with DM. The DM group subjects were followed up for over a year, and their fasting serum C-peptide levels remained at over $1.0 \mathrm{ng} / \mathrm{mL}$. The mean age and BMI of all subjects were $12.51 \pm 3.45$ years and $24.50 \pm 5.12 \mathrm{~kg} / \mathrm{m}^{2}$, respectively, and the BMI was similar between the NGT and glucose intolerance groups (IGT and DM). However, both the IGT and DM groups had female predominance compared to the NGT group $(P=0.004)$. Those with a family history of DM among the first-degree relatives were significantly more than those in the NGT group; however, they had no family history of type 1 diabetes. Table 2 provides 
TABLE 1: Demographic features of the study participants.

\begin{tabular}{|c|c|c|c|c|c|c|}
\hline \multirow{2}{*}{ Characteristic } & \multirow{2}{*}{ Total } & \multirow{2}{*}{ NGT } & \multicolumn{3}{|c|}{ Glucose intolerance } & \multirow{2}{*}{$\begin{array}{c}P \text { value }(\text { NGT versus IGT } \\
\text { versus DM) }\end{array}$} \\
\hline & & & IGT & $\mathrm{DM}$ & Subtotal & \\
\hline Number (\%) & $187(100.0)$ & $115(61.5)$ & $33(17.6)$ & $39(20.9)$ & 72 & \\
\hline Age (years) & $12.51 \pm 3.45$ & $11.76 \pm 3.56^{*}$ & $12.83 \pm 3.04^{*}$ & $14.47 \pm 2.54^{\dagger}$ & $13.72 \pm 2.88$ & $<0.001$ \\
\hline \multicolumn{7}{|l|}{ Sex (\%) } \\
\hline Female & $98(52.4)$ & $51(44.3)$ & $20(60.6)$ & $27(69.2)$ & $47(65.3)$ & 0.004 \\
\hline Male & $89(47.6)$ & $64(55.7)$ & $13(39.4)$ & $12(30.8)$ & $25(34.7)$ & \\
\hline $\begin{array}{l}\text { Family history of DM in the first- } \\
\text { degree relatives }\end{array}$ & $63(33.7)$ & $24(20.9)$ & $16(48.5)$ & $23(59.0)$ & $39(54.2)$ & $<0.001$ \\
\hline BMI $\left(\mathrm{kg} / \mathrm{m}^{2}\right)$ & $24.50 \pm 5.12$ & $23.95 \pm 4.68$ & $25.20 \pm 6.19$ & $25.54 \pm 5.29$ & $25.39 \pm 5.68$ & 0.170 \\
\hline Normal & $59(31.6)$ & $36(31.3)$ & $8(24.2)$ & $15(38.5)$ & $23(31.9)$ & 0.998 \\
\hline Overweight & $42(22.5)$ & $30(26.1)$ & $5(15.2)$ & $7(17.9)$ & $12(16.7)$ & \\
\hline Obesity & $86(46.0)$ & $49(42.6)$ & $20(60.6)$ & $17(43.6)$ & $37(51.4)$ & \\
\hline
\end{tabular}

The data are presented as mean \pm SD values. NGT, normal glucose tolerance; IGT, impaired glucose tolerance; DM, type 2 diabetes mellitus; BMI, body mass index; SD, standard deviation.

the clinical and laboratory characteristics of the study subjects. As expected, both the IGT and DM groups had significantly higher systolic blood pressure and FPG, C-peptide, insulin, HOMA-IR, total cholesterol, LDL cholesterol, triglyceride, and lower HDL cholesterol levels than the NGT group $(P<0.05)$. In addition, serum IGF-I and total IGFBP-3 levels were significantly higher in the IGT and DM groups than in the NGT group $(P<0.01)$, with the highest levels found in subjects with newly diagnosed DM. However, there was no difference in the IGF-I/IGFBP3 ratio among the three groups.

Because serum IGF-I and total IGFBP-3 showed correlation with BMI, we examined whether serum IGF-I and total IGFBP-3 levels vary with BMI in subjects with glucose intolerance (Table 3). The normal weight group, overweight group, and obesity group included 23 (31.9\%), 12 (16.7\%), and $37(51.4 \%)$ subjects, respectively. Although there were significant differences in age; systolic blood pressure; and serum C-peptide, insulin, HDL cholesterol, and triglyceride levels between normal, overweight, or obese subjects, serum IGF-I and total IGFBP-3 levels were not different among the three groups $(P>0.05)$. These data suggest that alterations in IGF-I and total IGFBP-3 levels resulted from glucose intolerance, but not from obesity.

Finally, the correlation between IGF-I and total IGFBP-3 levels based on clinical and laboratory parameters of the study subjects was analyzed using the Pearson correlation coefficient (Tables 4 and 5). In the NGT group, serum IGF-I levels were positively correlated with age, FPG, HOMA-IR, HbA1c, serum C-peptide, insulin, and total IGFBP-3 levels, while serum total IGFBP-3 levels were correlated with age, BMI, HOMA-IR, serum C-peptide, insulin, HbA1c, triglyceride, and IGF-I levels. However, these relationship patterns were different in patients with glucose intolerance, especially in those with DM. In DM subjects, serum IGF-I was positively correlated with FPG, HbA1c, and total IGFBP-3 levels, while the serum total IGFBP-3 level was correlated with FPG, $\mathrm{HbA1c}$, and LDL cholesterol levels. In contrast, the serum total IGFBP-3 level was not correlated with age, BMI, serum insulin, or HOMA-IR.

\section{Discussion}

We found that high serum IGF-I and total IGFBP-3 levels were associated with glucose intolerance and that these associations with clinical variables were altered according to glucose tolerance status, suggesting that the IGF-I-IGFBP-3 axis plays an important role in the pathogenesis and metabolic control of glucose intolerance, especially in DM. To the best of our knowledge, this is the first study to report that IGFBP-3 is related to glucose intolerance in children and adolescents with naïve type 2 diabetes.

Insulin is the major regulator of glucose homeostasis. Like insulin, the GH-IGF-IGFBP axis may also play a role in maintaining glucose metabolism. IGF-I is a hormone that resembles insulin in structure and is synthesized mainly by the liver when stimulated by growth hormones. The receptors for IGF-I and insulin are similar [3]; thus, they share several identical signaling pathways and cell and biological responses $[3,26]$. Therefore, the distinction between the roles of insulin and IGF-1 as causes of diabetes and progression of insulin-resistant states is unclear. Many experimental and clinical studies have suggested that circulating IGF-I is important for glucose regulation. Several studies have reported a positive correlation between IGF-I, insulin resistance, and glucose metabolism $[14,15]$; IGF-I was found to improve blood sugar control and insulin sensitivity in healthy adults and DM patients $[13,27]$.

IGFBP-3, the most abundant circulating IGFBP, may play an important role in blood glucose control and vice versa with IGF-1 in metabolic effects [28]. IGFBP-3 inhibits the bioactivity of IGF-I through binding, thereby reducing the concentration of free IGF-I in circulation and increasing the risk of DM [27-29]. IGFBP-3 also reduces glucose uptake by insulin through decreased insulin-stimulated glucose transporter-4 translocation to the plasma membrane and threonine phosphorylation of Akt [3]. These findings may suggest that serum IGF-I and IGFBPs levels have an impact on the risk of developing DM.

Some research confirmed the role of the IGF-I-IGFBP-3 axis in normal glucose homeostasis and its possible 


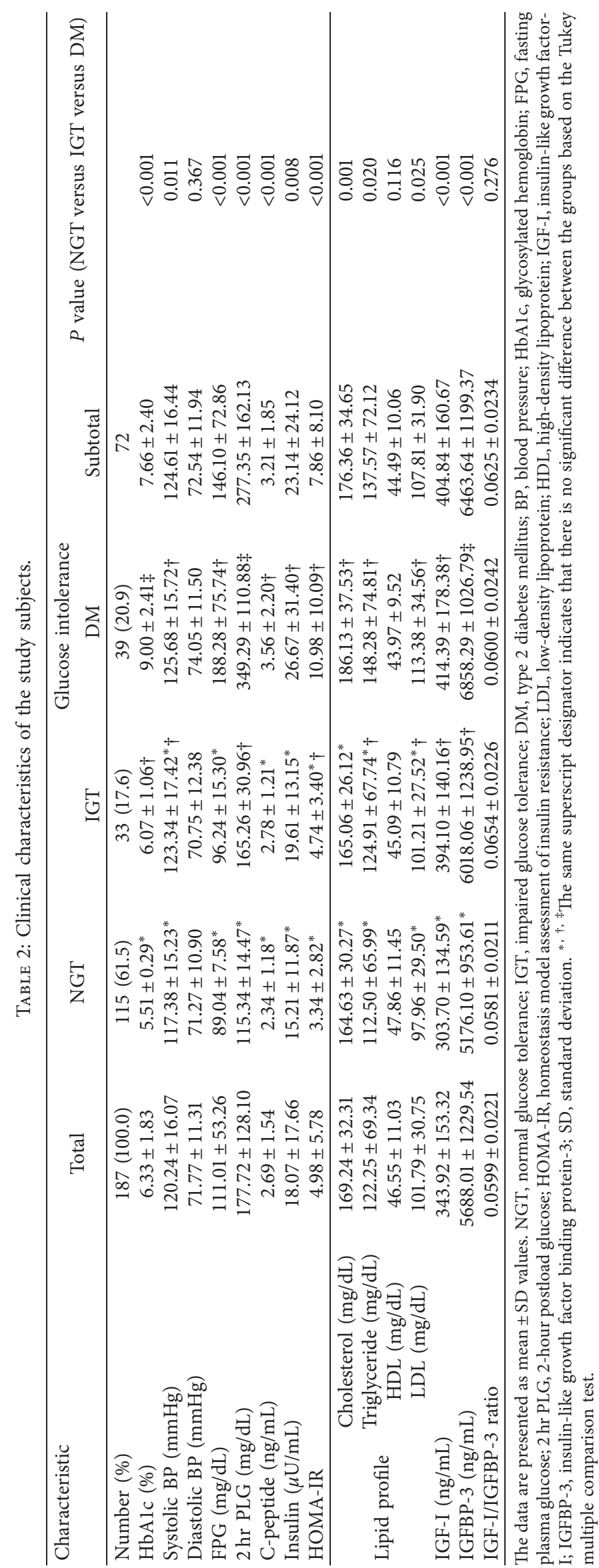


TABLE 3: Clinical characteristics of the study subjects with glucose intolerance according to BMI.

\begin{tabular}{|c|c|c|c|c|c|c|}
\hline \multicolumn{2}{|l|}{ Characteristic } & Total & Normal & Overweight & Obesity & $P$ value \\
\hline \multicolumn{2}{|l|}{ Number (\%) } & $72(100.0)$ & $23(31.9)$ & $12(16.7)$ & $37(51.4)$ & \\
\hline \multicolumn{2}{|c|}{ Sex (male/female) } & $25 / 47$ & $8 / 15$ & $5 / 7$ & $12 / 25$ & 0.812 \\
\hline \multicolumn{2}{|l|}{ Age (yr) } & $13.72 \pm 2.88$ & $15.32 \pm 2.47^{*}$ & $13.13 \pm 3.08 \dagger$ & $12.92 \pm 2.71 \dagger$ & 0.004 \\
\hline \multicolumn{2}{|l|}{ BMI $\left(\mathrm{kg} / \mathrm{m}^{2}\right)$} & $25.39 \pm 5.68$ & $20.41 \pm 2.91^{*}$ & $23.05 \pm 5.03^{*}$ & $29.24 \pm 4.22 \dagger$ & $<0.001$ \\
\hline \multicolumn{2}{|l|}{ HbAlc (\%) } & $7.66 \pm 2.40$ & $7.98 \pm 2.92$ & $7.55 \pm 2.37$ & $7.49 \pm 2.10$ & 0.743 \\
\hline \multicolumn{2}{|c|}{ Systolic BP (mmHg) } & $124.61 \pm 16.44$ & $117.48 \pm 14.31^{*}$ & $132.55 \pm 15.59 \dagger$ & $126.75 \pm 16.63^{*} \dagger$ & 0.021 \\
\hline \multicolumn{2}{|c|}{ Diastolic BP (mmHg) } & $72.54 \pm 11.94$ & $70.87 \pm 11.89$ & $70.27 \pm 7.43$ & $74.31 \pm 13.02$ & 0.448 \\
\hline \multicolumn{2}{|l|}{$\mathrm{FPG}(\mathrm{mg} / \mathrm{dL})$} & $146.10 \pm 72.86$ & $156.52 \pm 75.47$ & $150.08 \pm 67.18 \mathrm{WSY}$ & $138.32 \pm 73.98$ & 0.635 \\
\hline \multicolumn{2}{|c|}{2 hr PLG (mg/dL) } & $277.35 \pm 162.13$ & $309.35 \pm 142.62$ & $319.08 \pm 269.74$ & $243.92 \pm 121.64$ & 0.197 \\
\hline \multicolumn{2}{|c|}{ C-peptide (ng/mL) } & $3.21 \pm 1.85$ & $1.87 \pm 0.82^{*}$ & $3.85 \pm 2.32 \dagger$ & $3.85 \pm 1.73 \dagger$ & $<0.001$ \\
\hline \multicolumn{2}{|c|}{ Insulin $(\mu \mathrm{U} / \mathrm{mL})$} & $23.14 \pm 24.12$ & $9.04 \pm 5.08^{*}$ & $30.16 \pm 27.33 \dagger$ & $29.06 \pm 26.77 \dagger$ & 0.013 \\
\hline \multicolumn{2}{|l|}{ HOMA-IR } & $7.86 \pm 8.10$ & $4.08 \pm 3.45^{*}$ & $9.02 \pm 7.07^{*} \dagger$ & $9.63 \pm 9.52 \dagger$ & 0.067 \\
\hline \multirow{4}{*}{ Lipid profile } & Cholesterol (mg/dL) & $176.47 \pm 34.25$ & $169.87 \pm 40.92$ & $183.33 \pm 30.46$ & $178.35 \pm 30.98$ & 0.491 \\
\hline & Triglyceride (mg/dL) & $137.57 \pm 72.12$ & $95.09 \pm 44.26^{*}$ & $147.50 \pm 68.86 \dagger$ & $160.76 \pm 76.64 \dagger$ & 0.002 \\
\hline & $\mathrm{HDL}(\mathrm{mg} / \mathrm{dL})$ & $44.49 \pm 10.06$ & $48.74 \pm 13.63^{*}$ & $45.42 \pm 8.11^{*} \dagger$ & $41.54 \pm 6.74 \dagger$ & 0.023 \\
\hline & LDL (mg/dL) & $107.81 \pm 31.90$ & $100.26 \pm 41.53$ & $111.67 \pm 21.12$ & $111.24 \pm 27.63$ & 0.394 \\
\hline \multicolumn{2}{|c|}{ IGF-I (ng/mL) } & $404.84 \pm 160.67$ & $409.49 \pm 123.89$ & $441.71 \pm 157.09$ & $391.76 \pm 182.44$ & 0.682 \\
\hline \multicolumn{2}{|c|}{ IGFBP-3 (ng/mL) } & $6463.64 \pm 1199.37$ & $6390.00 \pm 1079.20$ & $6206.00 \pm 1487.64$ & $6587.06 \pm 1203.85$ & 0.643 \\
\hline \multicolumn{2}{|c|}{ IGF-I/IGFBP-3 ratio } & $0.0625 \pm 0.0234$ & $0.0646 \pm 0.0187$ & $0.712 \pm 0.0233$ & $0.0587 \pm 0.0259$ & 0.298 \\
\hline
\end{tabular}

The data are presented as mean \pm SD values. BMI, body mass index; BP, blood pressure; HbAlc, glycosylated hemoglobin; FPG, fasting plasma glucose; $2 \mathrm{hr}$ PLG, 2-hour postload glucose; HOMA-IR, homeostasis model assessment of insulin resistance; LDL, low-density lipoprotein; HDL, high-density lipoprotein; IGF-I, insulin-like growth factor-I; IGFBP-3, insulin-like growth factor binding protein-3; SD, standard deviation. *, †, * The same superscript indicates that there is no significant difference between the groups based on the Tukey multiple comparison test.

TABLE 4: Simple correlation $(\gamma)$ analysis between serum IGF-I and clinical variables.

\begin{tabular}{|c|c|c|c|c|c|c|c|}
\hline & & \multicolumn{2}{|c|}{ NGT $(n=115)$} & \multicolumn{2}{|c|}{ IGT $(n=33)$} & \multicolumn{2}{|c|}{$\mathrm{DM}(n=39)$} \\
\hline & & $P$ & $\gamma$ & $P$ & $\gamma$ & $P$ & $\gamma$ \\
\hline \multirow{13}{*}{ IGF-I } & Age & $<0.001$ & 0.475 & 0.612 & 0.093 & 0.353 & -0.159 \\
\hline & BMI & 0.895 & -0.013 & 0.487 & 0.127 & 0.080 & -0.296 \\
\hline & FPG & 0.014 & 0.242 & 0.482 & -0.129 & 0.001 & 0.544 \\
\hline & $2 \mathrm{hr}$ PLG & 0.965 & 0.004 & 0.252 & -0.208 & 0.729 & 0.060 \\
\hline & Cholesterol & 0.459 & -0.074 & 0.514 & 0.120 & 0.820 & -0.039 \\
\hline & Triglyceride & 0.914 & 0.011 & 0.214 & 0.226 & 0.354 & -0.159 \\
\hline & $\mathrm{HDL}$ & 0.454 & 0.075 & 0.876 & 0.029 & 0.338 & 0.164 \\
\hline & LDL & 0.148 & -0.144 & 0.862 & -0.032 & 0.897 & -0.022 \\
\hline & HOMA-IR & 0.004 & 0.294 & 0.349 & 0.184 & 0.176 & 0.268 \\
\hline & HbA1c & 0.039 & 0.204 & 0.717 & -0.067 & 0.028 & 0.367 \\
\hline & C-peptide & 0.001 & 0.330 & 0.142 & 0.270 & 0.609 & -0.088 \\
\hline & Insulin & 0.008 & 0.270 & 0.279 & 0.212 & 0.914 & -0.022 \\
\hline & IGFBP-3 & $<0.001$ & 0.547 & 0.085 & 0.315 & 0.029 & 0.368 \\
\hline
\end{tabular}

NGT, normal glucose tolerance; IGT, impaired glucose tolerance; DM, type 2 diabetes. BMI, body mass index; HbAlc, glycosylated hemoglobin; FPG, fasting plasma glucose; 2 hr PLG, 2-hour postload glucose; HOMA-IR, homeostasis model assessment of insulin resistance; LDL, low-density lipoprotein; HDL, high-density lipoprotein; IGF-I, insulin-like growth factor-I; IGFBP-3, insulin-like growth factor binding protein-3.

contribution to the etiopathogenesis of DM [30, 31]. Several studies have shown elevated free IGF-I and IGFBP-3 levels and decreased IGFBP-1 levels in IGT and DM patients $[31,32]$. In the current study, serum IGF-I levels were significantly higher in individuals with glucose intolerance and were correlated with FPG and $\mathrm{HbA1c}$, but not with serum C-peptide, insulin, and HOMA-IR. We believe the increased IGF-I level in the glucose intolerance state possibly triggered the pathological condition. Further, the onset of $\mathrm{DM}$ and IGT is characterized by insulin resistance, hyperinsulinemia, insulin stimulation of IGF-I production in the liver through the upregulated GH signaling pathway (e.g., upregulated expression of the hepatic $\mathrm{GH}$ receptor), and decreased IGFBP-1 level [3, 33]. Hyperinsulinemia, through an increased intraportal insulin concentration, causes an increase in hepatic IGF-I production [34], as seen in this study's results. Accordingly, the high serum IGF-I level in DM patients may be caused by high insulin levels, rather than reflecting the biological role of the IGF axis on DM pathogenesis [35]. In addition, Sandhu et al. [35] found a negative association between IGF-I levels and the risk of developing IGT/DM in patients after 4.5 years of follow-up. Yuen et al. [36, 37] found that serum GH concentration and its direct effects on insulin suppression of hepatic 
TABLE 5: Simple correlation $(\gamma)$ between serum IGFBP-3 and clinical variables.

\begin{tabular}{|c|c|c|c|c|c|c|c|}
\hline & & \multicolumn{2}{|c|}{ NGT $(n=115)$} & \multicolumn{2}{|c|}{ IGT $(n=33)$} & \multicolumn{2}{|c|}{$\mathrm{DM}(n=39)$} \\
\hline & & $P$ & $\gamma$ & $P$ & $\gamma$ & $P$ & $\gamma$ \\
\hline \multirow{13}{*}{ IGFBP-3 } & Age & 0.002 & 0.307 & 0.973 & 0.006 & 0.625 & 0.086 \\
\hline & BMI & 0.031 & 0.215 & 0.006 & 0.480 & 0.967 & -0.007 \\
\hline & FPG & 0.117 & 0.158 & 0.304 & 0.191 & 0.012 & 0.421 \\
\hline & $2 \mathrm{hr}$ PLG & 0.682 & 0.041 & 0.225 & 0.224 & 0.086 & -0.294 \\
\hline & Cholesterol & 0.547 & 0.061 & 0.029 & 0.392 & 0.008 & 0.442 \\
\hline & Triglyceride & 0.008 & 0.266 & 0.013 & 0.441 & 0.200 & 0.222 \\
\hline & HDL & 0.997 & 0.000 & 0.145 & -0.268 & 0.529 & 0.110 \\
\hline & LDL & 0.785 & -0.028 & 0.018 & 0.423 & 0.047 & 0.354 \\
\hline & HOMA-IR & 0.019 & 0.242 & $<0.001$ & 0.670 & 0.294 & -0.210 \\
\hline & HbAlc & 0.003 & 0.296 & 0.019 & 0.420 & 0.004 & 0.477 \\
\hline & C-peptide & 0.010 & 0.259 & $<0.001$ & 0.661 & 0.068 & -0.312 \\
\hline & Insulin & 0.021 & 0.237 & $<0.001$ & 0.626 & 0.070 & -0.354 \\
\hline & IGF-I & $<0.001$ & 0.547 & 0.085 & 0.315 & 0.029 & 0.368 \\
\hline
\end{tabular}

NGT, normal glucose tolerance; IGT, impaired glucose tolerance; DM, type 2 diabetes. BMI, body mass index; HbAlc, glycosylated hemoglobin; FPG, fasting plasma glucose; HOMA-IR, homeostasis model assessment of insulin resistance; LDL, low-density lipoprotein; HDL, high-density lipoprotein; IGF-I, insulinlike growth factor-I; IGFBP-3, insulin-like growth factor binding protein-3.

gluconeogenesis are reduced by IGF-I; IGF-I also indirectly enhances hepatic insulin action by increasing fatty acid uptake in muscles. Further, Ricotti et al. [38] reported the relationship between decreased serum IGF-I and high blood glucose level, insulin, and insulin resistance. In a murine model, IGF-I may play an important role in improving glucose tolerance and insulin sensitivity [39]. These data support that an increased IGF-I could inhibit the progression of glucose intolerance states and their complications. Although serum IGF-I is negatively related to HbA1c in DM [40], it was positively correlated with FPG and HbAlc levels in the current study, suggesting a significant negative role for serum IGF-I in metabolic control of DM. Abbas et al. [41] suggested that the absence of prospective studies on the progression of insulin resistance and the unclear measurement of free or total IGF-I concentration caused the various results obtained regarding the relationship of IGF-1/glucose metabolism. Moreover, they reported that the role of IGF-I in glucose homeostasis has not yet been completely elucidated. Therefore, it is necessary to study factors affecting IGF-I bioactivity, such as IGFBPs; further studies are also needed to understand the unclear mechanism.

Recent studies indicated that dysregulated IGF-1/IGFBP levels could cause IGT [42]. Of note, IGFBPs have an important role in the development of obesity, insulin resistance, and metabolic syndrome. Cross-sectional studies revealed that serum IGFBP-3 levels were elevated in patients with $\mathrm{DM}$ and positive correlations were observed between fasting insulin and C-peptide levels $[26,43]$. In our study, total serum IGFBP-3 levels were significantly elevated in DM patients and were positively correlated with FPG, HbAlc, total cholesterol, and IGF-I levels. IGFBP-3, a slower regulator of free IGF-I than IGFBP-1, is regulated by GH and IGF-I and has marked contrasting and independent physiological effects on peripheral insulin action [28]. Therefore, high IGFBP-3 levels may be a risk factor for DM. Rajpathak et al. reported that serum IGFBP-3 levels have strong positive correlations with the risk of DM in women [17]. The positive relationship between IGFBP-3 and lipid profiles in glucose intolerance state shown in the current study is consistent with the findings of reports about their metabolism $[44,45]$. These findings suggest that measurement of total serum IGFBP-3 levels may be informative for determining its association with DM. However, the functional significance of IGFBP-3 in the pathoetiology of DM is largely unknown. Previous studies provided evidence for the direct involvement of IGFBP-3 in metabolic disorders, as increased IGFBP-3 fragments in circulation have been observed in catabolic states such as diabetes and obesity, leading to a decrease in total IGFBP- 3 concentration $[10,46]$. IGFBP-3 was also reported to inhibit cytokine-induced insulin resistance and early manifestation of atherosclerosis independent of IGF in the study by Mohanraj et al. [46]. They proved the fundamental concept regarding the proteolyzed IGFBP-3. The total IGFBP-3 decreased while proteolyzed IGFBP-3 increased in the serum of overweight and obese adolescents when compared with the control group. They reported that the sera of overweight and obese adolescents had significantly decreased intact IGFBP-3 through an increase in the production of proteolytic fragments. Consequently, the decreased circulating intact IGFBP-3 levels suppressed the anti-inflammatory and insulin-sensitizing functions of IGBPB-3 [46]. Interestingly, another observational study showed that total IGF-I and IGFBP-3 levels were not associated with the risk of DM [47].

Nevertheless, the current study demonstrated that serum IGF-I and total IGFBP-3 levels were not different among normal BMI, overweight, and obese subgroups and therefore were not correlated with BMI. This suggests that obesity has little impact on total IGFBP-3 levels in our study subjects.

From 2016 to 2018, in South Koreans aged 10 to 18 years, the prevalence of diabetes was $0.43 \%$ [48], and ours is one of the countries with the lowest incidence of diabetes. However, the prevalence of diabetes in our study population is high, and similar finding has already been reported by other authors. We had reported the prevalence of diabetes (36.4\%, $n=40 / 110$ ) in renal glycosuria in our province [18]. Moreover, of 21 students with glycosuria, 8 were diagnosed 
with diabetes [19], and in a Japanese study [20], of 298 glycosuric children, $133(44.6 \%)$ students developed diabetes.

This study had some limitations. First, the comparison between NGT and IGT or DM groups was difficult due to the relatively small number of patients. Second, as we did not measure serum insulin levels during OGTT, we could not examine the relationships between IGF-I, IGFBP-3, and insulinogenic and disposition indexes. Third, our data did not include clinical parameters reflecting metabolic dysfunction adiposity, such as waist circumference (WC) and WC-to-height ratio, other than BMI. Finally, another limitation is that we did not measure serum-free IGF-I, IGFBP1 , and functional IGFBP-3 levels or perform genetic studies. Further studies are required to document the role of the IGFI-IGFBP-3 axis in the development of glucose intolerance, especially in patients with T2DM and insulin resistance.

\section{Conclusions}

In summary, the present study showed that serum IGF-I and total IGFBP-3 levels are elevated in IGT and DM subjects with positive correlations with FPG and HbA1c; serum IGFBP-3 levels are also positively correlated with cholesterol levels. These findings suggest that the IGF-I-IGFBP-3 axis might be associated with diabetes risk and metabolic control in patients with glucose intolerance. Thus, we believe that the IGF-I-IGFBP-3 axis, especially IGFBP-3, could serve as a useful therapeutic target for the treatment of diabetes.

\section{Data Availability}

The data used to support the findings of this study are available from the corresponding author upon reasonable request.

\section{Conflicts of Interest}

The authors declare that there are no conflicts of interest.

\section{Acknowledgments}

This work was supported by the National Research Foundation of Korea (NRF) grant funded by the Korean government (MSIT) (no. 2020R1A2C1014890).

\section{References}

[1] D. Dabelea, E. J. Mayer-Davis, S. Saydah et al., "Prevalence of type 1 and type 2 diabetes among children and adolescents from 2001 to 2009," JAMA, vol. 311, no. 17, pp. 1778-1786, 2014.

[2] E.-H. Cho, D. Shin, K.-H. Cho, and J. Hur, "Prevalences and management of diabetes and pre-diabetes among Korean teenagers and young adults: results from the Korea national health and nutrition examination survey 2005-2014," Journal of Korean Medical Science, vol. 32, no. 12, pp. 1984-1990, 2017.

[3] N. J. Haywood, T. A. Slater, C. J. Matthews, and S. B. Wheatcroft, "The insulin like growth factor and binding protein family: novel therapeutic targets in obesity \& diabetes," Molecular Metabolism, vol. 19, pp. 86-96, 2019.
[4] E. Osher and V. M. Macaulay, "Therapeutic targeting of the IGF axis," Cells, vol. 8, no. 8, p. 895, 2019.

[5] D. Le Roith, "Insulin-like growth factors," New England Journal of Medicine, vol. 336, no. 9, pp. 633-640, 1997.

[6] R. C. Baxter and J. L. Martin, "Binding proteins for the insulin-like growth factors: structure, regulation and function," Progress in Growth Factor Research, vol. 1, no. 1, pp. 49-68, 1989.

[7] J. I. Jones and D. R. Clemmons, "Insulin-like growth factors and their binding proteins: biological actions," Endocrine Reviews, vol. 16, no. 1, pp. 3-34, 1995.

[8] L. Jin, F. Shen, M. Weinfeld, and C. Sergi, "Insulin growth factor binding protein 7 (IGFBP7)-related cancer and IGFBP3 and IGFBP7 crosstalk," Frontiers in Oncology, vol. 10, p. 727, 2020.

[9] M. S. Kim and D.-Y. Lee, "Insulin-like growth factor (IGF)-I and IGF binding proteins axis in diabetes mellitus," Annals of Pediatric Endocrinology \& Metabolism, vol. 20, no. 2, pp. 69-73, 2015.

[10] S. Jogie-Brahim, D. Feldman, and Y. Oh, "Unraveling insulinlike growth factor binding protein-3 actions in human disease," Endocrine Reviews, vol. 30, no. 5, pp. 417-437, 2009.

[11] G. E. Walker, H. S. Kim, Y. F. Yang, and Y. Oh, "IGF-independent effects of the IGF superfamily," in Insulin-like Growth Factors, D. Le Roith, W. Zumkeller, and R. Baxter, Eds., pp. 1-22, Landes Biosciences, Austin, Tx, USA, 2004.

[12] M. Gaddas, L. Périn, and Y. Le Bouc, "Evaluation of IGF1/ IGFBP3 molar ratio as an effective tool for assessing the safety of growth hormone therapy in small-for-gestational-age, growth hormone-deficient and Prader-Willi children," Journal of Clinical Research in Pediatric Endocrinology, vol. 11, no. 3, pp. 253-261, 2019.

[13] A. C. Moses, S. C. Young, L. A. Morrow, M. O’Brien, and D. R. Clemmons, "Recombinant human insulin-like growth factor I increases insulin sensitivity and improves glycemic control in type II diabetes," Diabetes, vol. 45, no. 1, pp. 91-100, 1996.

[14] Y. Shao, C. Lv, Q. Yuan, and Q. Wang, "Levels of serum $25(\mathrm{OH}) \mathrm{VD}_{3}, \mathrm{HIF}-1 \alpha$, VEGF, vWf, and IGF-1 and their correlation in type 2 diabetes patients with different urine albumin creatinine ratio," Journal of Diabetes Research, vol. 2016, Article ID 1925424, 7 pages, 2016.

[15] A. M. Hannon, C. J. Thompson, and M. Sherlock, "Diabetes in patients with acromegaly," Current Diabetes Reports, vol. 17, no. 2, p. 8, 2017.

[16] H. J. Schneider, N. Friedrich, J. Klotsche et al., "Prediction of incident diabetes mellitus by baseline IGF1 levels," European Journal of Endocrinology, vol. 164, no. 2, pp. 223-229, 2011.

[17] S. N. Rajpathak, M. He, Q. Sun et al., "Insulin-like growth factor axis and risk of type 2 diabetes in women," Diabetes, vol. 61, no. 9, pp. 2248-2254, 2012.

[18] M. S. Kim and D.-Y. Lee, "Urinary glucose screening for early detection of asymptomatic type 2 diabetes in Jeonbuk province Korean schoolchildren," Journal of Korean Medical Science, vol. 32, no. 6, pp. 985-991, 2017.

[19] Y. A. Batson, S. Teelucksingh, R. Maharaj, V. Singh, S. Balkaran, and B. Cockburn, "Screening for diabetes in schoolchildren in Trinidad, West Indies," Paediatrics and International Child Health, vol. 33, no. 1, pp. 37-41, 2013.

[20] E. Ogawa, T. Urakami, J. Suzuki, A. Yoshida, S. Takahashi, and H. Mugishima, "Usefulness of HbAlc to diagnose diabetes among Japanese children detected by a urine glucose screening program in the Tokyo metropolitan area," Endocrine Journal, vol. 59, no. 6, pp. 465-471, 2012. 
[21] T. Urakami, S. Morimoto, Y. Nitadori, K. Harada, M. Owada, and T. Kitagawa, "Urine glucose screening program at schools in Japan to detect children with diabetes and its outcomeincidence and clinical characteristics of childhood type 2 diabetes in Japan," Pediatric Research, vol. 61, no. 2, pp. 141-145, 2007.

[22] J. H. Kim, S. Yun, S.-S. Hwang et al., "The 2017 Korean national growth charts for children and adolescents: development, improvement, and prospects," Korean Journal of Pediatrics, vol. 61, no. 5, pp. 135-149, 2018.

[23] K. G. M. M. Alberti and P. Z. Zimmet, "Definition, diagnosis and classification of diabetes mellitus and its complications. part 1: diagnosis and classification of diabetes mellitus. provisional report of a WHO consultation," Diabetic Medicine, vol. 15, no. 7, pp. 539-553, 1998.

[24] J. Park, J. Oh, and J. Yu, "Autoantibody positivity and clinical characteristics of diabetes mellitus in childhood," Journal of Korean Society of Pediatric Endocrinology, vol. 16, no. 2, pp. 119-127, 2011.

[25] A. M. Freeman and N. Pennings, "Insulin resistance," StatPearls Publishing, Treasure Island, FL, USA, 2020.

[26] N. Rachdaoui, "Insulin: the friend and the foe in the development of type 2 diabetes mellitus," International Journal of Molecular Sciences, vol. 21, no. 5, p. 1770, 2020.

[27] D. L. Russell-Jones, A. T. Bates, A. M. Umpleby et al., "A comparison of the effects of IGF-I and insulin on glucose metabolism, fat metabolism and the cardiovascular system in normal human volunteers," European Journal of Clinical Investigation, vol. 25, no. 6, pp. 403-411, 1995.

[28] R. H. Muzumdar, X. Ma, S. Fishman et al., "Central and opposing effects of IGF-I and IGF-binding protein-3 on systemic insulin action," Diabetes, vol. 55, no. 10, pp. 2788-2796, 2006.

[29] J. V. Silha, Y. Gui, and L. J. Murphy, "Impaired glucose homeostasis in insulin-like growth factor-binding protein-3 transgenic mice," American Journal of Physiology: Endocrinology and Metabolism, vol. 283, no. 5, pp. 937-945, 2002.

[30] L. J. Murphy, "The role of the insulin-like growth factors and their binding proteins in glucose homeostasis," Experimental Diabesity Research, vol. 4, no. 4, pp. 213-224, 2003.

[31] S. N. Rajpathak, M. J. Gunter, J. Wylie-Rosett et al., "The role of insulin-like growth factor-I and its binding proteins in glucose homeostasis and type 2 diabetes," Diabetes/Metabolism Research and Reviews, vol. 25, no. 1, pp. 3-12, 2009.

[32] J. Frystyk, C. Skjærbæk, E. Vestbo, S. Fisker, and H. Ørskov, "Circulating levels of free insulin-like growth factors in obese subjects: the impact of type 2 diabetes," Diabetes/Metabolism Research and Reviews, vol. 15, no. 5, pp. 314-322, 1999.

[33] P. Bang, "Pediatric implications of normal insulin-GH-IGFaxis physiology," in Endotext, K. R. Feingold, B. Anawalt, A. Boyce et al., Eds., MDText.com, Inc., South Dartmouth, MA, USA, 2019.

[34] M. S. Kim and D. Y. Lee, "Serum insulin-like growth factorbinding protein-3 level correlated with glycemic control and lipid profiles in children and adolescents with type 1 diabetes," Journal of Pediatric Endocrinology and Metabolism, vol. 27, pp. 9-10, 2014.

[35] M. S. Sandhu, A. H. Heald, J. M. Gibson, J. K. Cruickshank, D. B. Dunger, and N. J. Wareham, "Circulating concentrations of insulin-like growth factor-I and development of glucose intolerance: a prospective observational study," The Lancet, vol. 359, no. 9319, pp. 1740-1745, 2002.

[36] K. C. J. Yuen and D. B. Dunger, "Therapeutic aspects of growth hormone and insulin-like growth factor-I treatment on visceral fat and insulin sensitivity in adults," Diabetes, Obesity and Metabolism, vol. 9, no. 1, pp. 11-22, 2007.

[37] D. R. Clemmons, "Metabolic actions of insulin-like growth factor-I in normal physiology and diabetes," Endocrinology and Metabolism Clinics of North America, vol. 41, no. 2, pp. 425-443, 2012.

[38] R. Ricotti, A. Solito, E. Mariotti Zani et al., "The relationship between cortisol and IGF-I influences metabolic alteration in pediatric overweight and obesity," European Journal of Endocrinology, vol. 182, no. 3, pp. 255-264, 2020.

[39] H. Hong, Z.-Z. Cui, L. Zhu et al., "Central IGF1 improves glucose tolerance and insulin sensitivity in mice," Nutrition \& Diabetes, vol. 7, no. 12, p. 2, 2017.

[40] I. Kanazawa, T. Yamaguchi, and T. Sugimoto, "Serum insulinlike growth factor-I is negatively associated with serum adiponectin in type 2 diabetes mellitus," Growth Hormone \& IGF Research, vol. 21, no. 5, pp. 268-271, 2011.

[41] A. Abbas, P. J. Grant, and M. T. Kearney, "Role of IGF-1 in glucose regulation and cardiovascular disease," Expert Review of Cardiovascular Therapy, vol. 6, no. 8, pp. 1135-1149, 2008.

[42] S. Pouriamehr, H. Barmaki, M. Rastegary, F. Lotfi, and M. Nabi Afjadi, "Investigation of insulin-like growth factors/ insulin-like growth factor binding proteins regulation in metabolic syndrome patients," BMC Research Notes, vol. 12, no. 1, p. 653, 2019.

[43] I. D. Bezemer, S. Rinaldi, L. Dossus et al., "C-peptide, IGF-I, sex-steroid hormones and adiposity: a cross-sectional study in healthy women within the European prospective investigation into cancer and nutrition (EPIC)," Cancer Causes \& Control, vol. 16, no. 5, pp. 561-572, 2005.

[44] M.-L. Eggert, H. Wallaschofski, A. Grotevendt et al., "Crosssectional and longitudinal relation of IGF1 and IGF-binding protein 3 with lipid metabolism," European Journal of Endocrinology, vol. 171, no. 1, pp. 9-19, 2014.

[45] J. Sierra-Johnson, A. Romero-Corral, V. K. Somers et al., "IGF-I/IGFBP-3 ratio: a mechanistic insight into the metabolic syndrome," Clinical Science, vol. 116, no. 6, pp. 507-512, 2009.

[46] L. Mohanraj, H.-S. Kim, W. Li et al., "IGFBP-3 inhibits cytokine-induced insulin resistance and early manifestations of atherosclerosis," PLoS One, vol. 8, no. 1, Article ID e55084, 2013.

[47] M. E. Similä, J. P. Kontto, J. Virtamo et al., "Insulin-like growth factor I, binding proteins -1 and -3 , risk of type 2 diabetes and macronutrient intakes in men," British Journal of Nutrition, vol. 121, no. 8, pp. 938-944, 2019.

[48] J. H. Kim and J. S. Lim, "Trends of diabetes and prediabetes prevalence among Korean adolescents from 2007 to 2018," Journal of Korean Medical Science, vol. 36, no. 17, p. e112, 2021. 